\title{
DEVELOPING A NOVEL BIO SENSOR FOR ETHANOL VAPOUR DETECTION
}

\author{
${ }^{1 *}$ Pavan Kalyan Reddy C.P., ${ }^{2}$ Roji Marjorie \\ ${ }^{1,2}$ Department of Electronics and Communication Engineering, Saveetha School of \\ Engineering, Saveetha Institute of Medical And Technical Sciences, Chennai, India. \\ Email: ${ }^{1}$ cppavan23@gmail.com, ${ }^{2}$ rojimarjorie@saveetha.com
}

\begin{abstract}
To prepare a novel Bio sensor for ethanol vapour detection with higher sensitivity. In this $\mathrm{Zn}(\mathrm{Mn}) / \mathrm{ZnO}$ inverted core shell structure is doped in starch. Add a noble metal foe the better response. After this making thin films and determine the thickness of a thin films. Dielectric constant is determined by using the LCR meter. The characterization is done by using XRD, SEM, and the sensing properties of ethanol sensor are based on the resistance-based sensing.
\end{abstract}

Keywords: biosensor, ethanol vapour detection, nano particles, LCR meter, $X R D, S E M$

\section{INTRODUCTION}

Ethanol sensor was the most important device to detect ethanol vapours in the alcoholic drinks, Gasoline, cosmetics and food products. The ethanol sensor was made with different types of semiconductor materials with the addition polymers and noble metals in the field of Nano. The addition of noble is metals for the better sensing properties. The ethanol was used in major products and it is harmful to include the excess of ethanol in any products like food and alcohol beverages for the cause of nerves problem. In the petrol there was a problem to damage the engine. For the reducing this damages we are using $\mathrm{Zn}(\mathrm{Mn}) / \mathrm{ZnO}$ Nano composite with addition of starch and noble metal for the better response and sensitivity of sensor. The other sensors are delay to detect the ethanol. While transporting the any type of gasoline with the other locations there was a change in temperature with varying of temperature in gasoline.

In this study we are using the $\mathrm{Zn}(\mathrm{Mn}) / \mathrm{ZnO}$ Nano composite for the better response time and sensitivity. The structure of inner layer was having more space and the outer layer of $\mathrm{ZnO}$ particles is fast way to combine the structure. There is a fast movement in electron recombination. There was a different method to develop an ethanol sensor. The methods are sol-gel method, chemical precipitation method and dip coating method. We are going with dip coating method because it is easy method to make thin films and having a better thickness of core shell structure. The characterization was done by using the XRD, TEM. The dielectric constant was studied by using the LCR meter. In this project the sensing of ethanol sensor was based on resistance based sensing. The sensing properties are studied in this paper.

\section{LITERATURE REVIEW}

Ali Mirzaei [1] et al., has conducted a review on $\mathrm{Fe}_{2} \mathrm{O}_{3} / \mathrm{Co}_{3} \mathrm{O}_{4}$ composite Nano particle ethanol sensor. In this paper the synthesis of $\mathrm{Fe}_{2} \mathrm{O}_{3} / \mathrm{Co}_{3} \mathrm{O}_{4}$ composite was used hydrothermal process. The characterization was done by using TEM, SEM, in this there was an improved in gas sensing properties with the increase in the modulation of a conduction 
channel. The barrier potential was formed at $\mathrm{Fe}_{2} \mathrm{O}_{3} / \mathrm{Co}_{3} \mathrm{O}_{4}$ between them and there was an strong oxygen adsorption with the p-type $\mathrm{Co}_{3} \mathrm{O}_{4}$, there was a creation of adsorption sites.

QiaoWang[2] et al., has conducted a review on selective resistive ethanol sensor with the Wdoped $\mathrm{NiO}$ and has been synthesised by using the electro spinning method. The response rate was $4 \% \mathrm{~W}-\mathrm{NiO}$ NTs to $100 \mathrm{ppm}$ ethanol. The response rate was increased significantly with the change in morphology, there was an increase in oxygen and the decrease in hole concentration in $\mathrm{NiO}$ by $\mathrm{W}$ doping. Based on theory of oxygen the absorption and adsorption, there was an increment in the sensor response time with the content of atmospheric oxygen and shorten the response time with the increase amount of adsorbed oxygen.

$\mathrm{Li}$ Zhang[3] et al., has developed a ethanol sensor, with the synthesis of $\mathrm{SnO}_{2}$ microspheres in the Hydrothermal process with no organic agent. The result of $\mathrm{SnO}_{2}$ microspheres was consist the number of Nano crystalline particles with the size of 2-5nm.the oxygen vacancies are exist on the $\mathrm{SnO}_{2}$ microspheres. The characterization was done by using the SEM, TEM, the as-prepared $\mathrm{SnO}_{2}$ microspheres was in mesoporous structure and has been more specific surface area. The response rate was reached to $3 \mathrm{~s}$ and $24 \mathrm{~s}$ continuously under $100 \mathrm{ppm}$ ethanol flows and the working temperature was under $230^{\circ} \mathrm{C}$. The response rate was increased to 24.9 at $230^{\circ} \mathrm{C}$. the better sensing of fabricated ethanol sensor was attribute to small grain size, with high specific surface area and more number of oxygen vacancies of $\mathrm{SnO}_{2}$. The as-prepared microspheres -shaped $\mathrm{SnO}_{2}$ was an excellent ethanol sensor material. Hua-Liang $\mathrm{Yu}[4]$ et al., $\mathrm{WO}_{3}$ gas detecting material was developed by using hydrothermal method, showing a belt-like surface morphology. By contrasting and examining the UV-vis absorption spectra, they were indicated that the band gap of $\mathrm{WO}_{3}$ Nano-belts $(\mathrm{NBs})$ is $0.56 \mathrm{eV}$ greater than that of $\mathrm{WO}_{3}$ Nano-particles (NPs).Spectra and SPV stage spectra was shows that the course of the surface implicit electric field was in the form of the surface to the greater part of $\mathrm{WO}_{3} \mathrm{NBs}$ and the surface band bowing is upwards. $\mathrm{WO}_{3} \mathrm{NBs}$ based pho-to electric gas sensor was assembled for recognizing the high concentration of $\mathrm{C}_{2} \mathrm{H}_{5} \mathrm{OH}$ at room temperature. The outcomes show that the $\mathrm{WO}_{3} \mathrm{NBs}$ based photoelectric sensor was displays higher sensitivity and resolution to high concentration (1000 ppm-20000 ppm) of ethanol at room temperature than $\mathrm{WO}_{3} \mathrm{NPsbased}$ photoelectric sensor. $\mathrm{WO}_{3} \mathrm{NBs}$ was promising a gas detecting material used to fabricate photoelectric gas sensor for high concentration $\mathrm{C}_{2} \mathrm{H}_{5} \mathrm{OH}$ detection was working under the room temperature.

\section{MATERIALS AND METHODOLOGY}

We are using the Dip coating method to developed An Ethanol sensor, By adding 0.3g of Starch and $\mathrm{Zn}(\mathrm{Mn}) / \mathrm{ZnO}$ with the same ratios of mixture and add $50 \mathrm{ml}$ of water to this solution, and take another sample $0.7 \mathrm{~g}$ of starch and $\mathrm{Zn}(\mathrm{Mn}) / \mathrm{ZnO}$ mixture of same ratio, add $100 \mathrm{ml}$ of water and stir it for 15 minutes at 70 degrees temperature Then decrease to a Room temperature. For maintaining the $\mathrm{pH}$ value 10 add $\mathrm{NaOH}$, And forms as a Gel then paste it to a glass plate dry it leave for 1 or 2 days to form fringes and using this films we can find thickness of glass sheet by using the sodium vapor lamp and characterization is done with the reference of Resistance based sensing element. The optical and physical properties are resistor, capacitor and impedance using LCR meter. The sensing of ethanol sensor is based on the resistance based sensing. 


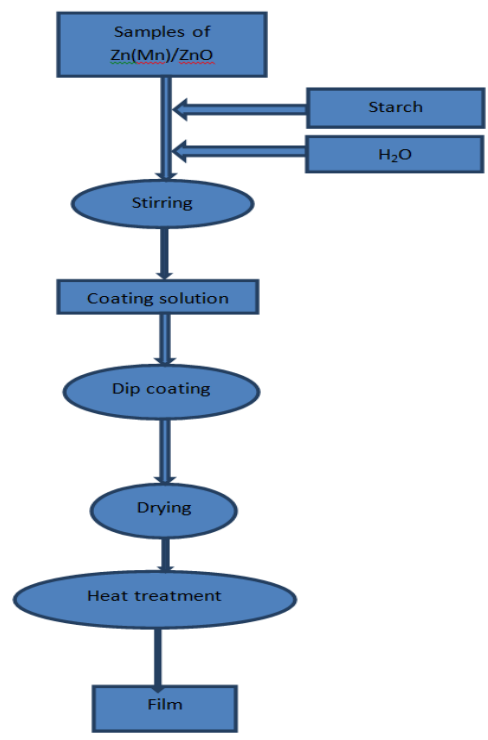

Fig. 1 The flow chart of the making films

\section{RESULTS}

In this paper, the results are based on the Electrical properties are $\mathrm{J}-\mathrm{V}$ characteristics and Impedance. The optical properties are used to find the coated on the glass plate using the Ultraviolent-visible near infrared 3400 spectra meter. Then the sensing element is based on resistance based sensing. The capacitor storage element is in high standard. In the characteristics of $\mathrm{J}-\mathrm{V}$ there is an increment in the both current density and voltage. There is a decrease in impedance with respect to the frequency in $\mathrm{MHz}$.

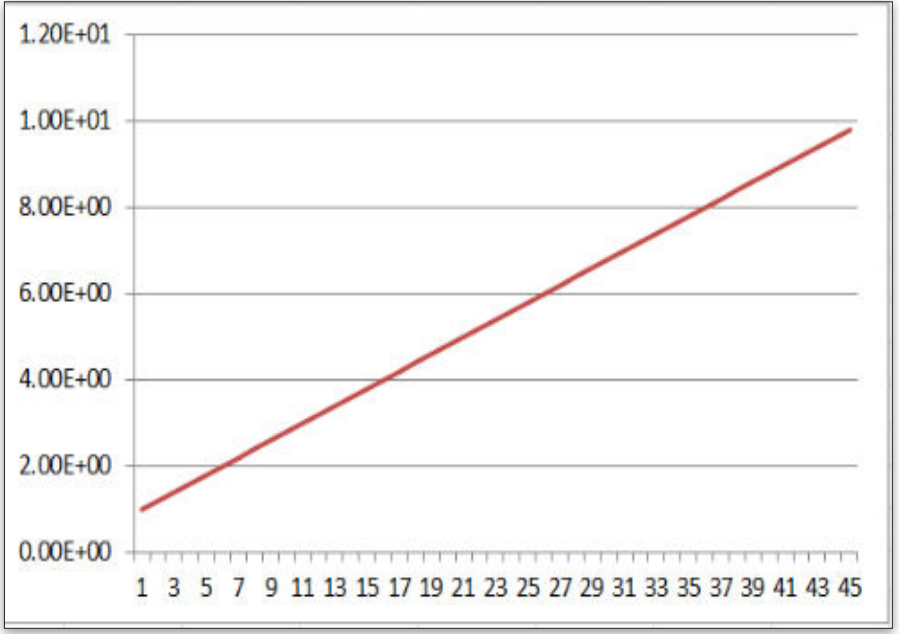

Fig.2 The graph between the Current density and Voltage 


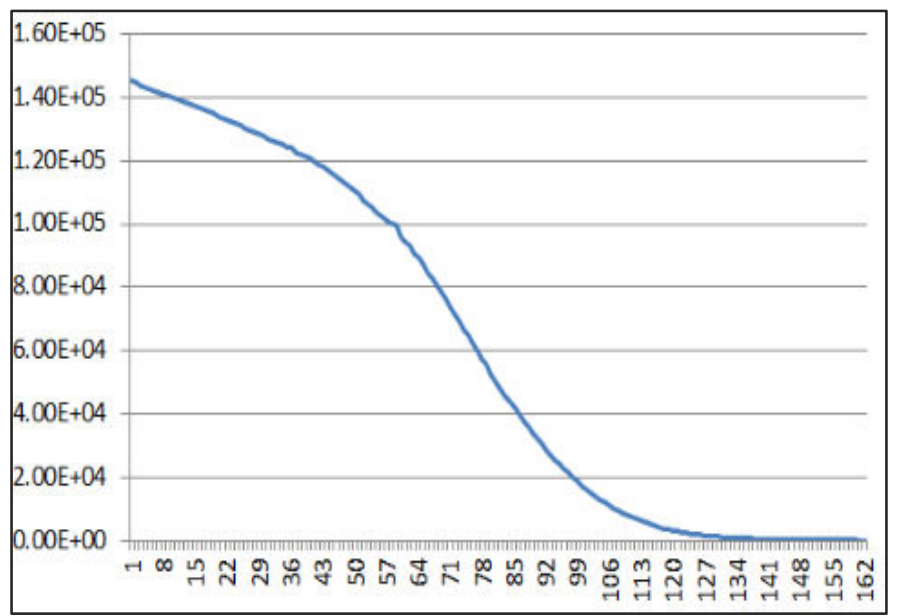

Fig.3 The graph between Impedance and Frequency.

\section{CONCLUSION}

The Nano particles of $\mathrm{Zn}(\mathrm{Mn}) / \mathrm{ZnO}$ material and starch polymer were prepared by using the dip coating method. It is easy method to develop with less cost. The prepared samples are characterized by based on the resistance method. The sensing of an ethanol sensor is high with resistance based sensing method. We calculated the characteristics of AC and DC. The current density and voltage are linearly increasing. The resistance value is $1025 \mathrm{k} \mathrm{ohm}$.

\section{REFERENCES}

[1]. Jankovic, Mrdjan, and Dave Hagner. "Twin-model method for ethanol detection in flex fuel vehicles." 2013 American Control Conference. IEEE, 2013.

[2]. Wang, Qiao, et al. "W-doped $\mathrm{NiO}$ as a material for selective resistive ethanol sensors." Sensors and Actuators B: Chemical 308 (2020): 127668.

[3]. Zhang, Li, et al. "Facile one-step hydrothermal synthesis of $\mathrm{SnO} 2$ microspheres with oxygen vacancies for superior ethanol sensor." Journal of Alloys and Compounds 814 (2020): 152266.

[4]. Song, Zhichao, Jun Zhang, and Jialiang Jiang. "Morphological evolution, luminescence properties and a high-sensitivity ethanol gas sensor based on 3D flower-like MoS2-ZnO micro/nanosphere arrays." Ceramics International 46.5 (2020): 6634-6640..

[5]. Maity, Debasis, Krishnamoorthy Rajavel, and Ramasamy Thangavelu Rajendra Kumar. "Polyvinyl alcohol wrapped multiwall carbon nanotube (MWCNTs) network on fabrics for wearable room temperature ethanol sensor." Sensors and Actuators B: Chemical 261 (2018): 297-306.

[6]. Hu, Peiguang, et al. "Enhancement of ethanol vapor sensing of $\mathrm{TiO} 2$ nanobelts by surface engineering." ACS applied materials \& interfaces 2.11 (2010): 3263-3269.

[7]. Li, Xian, et al. "Ethanol gas sensors based on copper phthalocyanine thin-film transistors." The 2010 International Conference on Apperceiving Computing and Intelligence Analysis Proceeding. IEEE, 2010..

[8]. Yang, Zunxian, et al. "Ethanol gas sensor based on Al-doped $\mathrm{ZnO}$ nanomaterial with many gas diffusing channels." Sensors and Actuators B: Chemical 140.2 (2009): 549556. 